Archived version from NCDOCKS Institutional Repository http://libres.uncg.edu/ir/asu/

\title{
Appalachỉan
}

B O O N E, N O R T H C A R O L I N A

\section{Teaching Family Systems Theory: A Developmental-Constructivist Perspective}

\author{
By: Karen Caldwell and Charles Claxton
}

\begin{abstract}
Kegan's (1994) "In Over Our Heads" phenomenon has much to offer those who engage in teaching family systems theory and therapy, particularly in relationship to the tensions involved in the potential mismatch between the developmental demands of the curriculum and orders of consciousness which characterize students " responses to the material. One useful way to think about teaching in ways that address the phenomenon that Kegan has named is David Kolb "s (1984) theory of experiential learning. Specific applications of this theory to teaching family systems theory are presented, as well issues involved in professional development based on the challenge this Kegan and Kolb developmental-constructivist perspective brings to department or program culture in which a family systems theory curriculum operates.
\end{abstract}

Caldwell, Karen \& Claxton, Charles. (2009). Teaching family systems theory: A developmentalconstructivist perspective. Contemporary Family Therapy, 32, 3-21. Published by Springer Verlag The original publication is available at www.springerlink.com (ISSN: 0892-2764) March 2010 \{DOI: 10.1007/ s10591-009-9106-6\} 
Caldwell, K., \& Claxton, C. (2009). Teaching family systems theory: A developmentalconstructivist perspective. Contemporary Family Therapy, 32, 3-21. Published by Springer Verlag The original publication is available at www.springerlink.com (ISSN: 0892-2764) March 2010 DOI: 10.1007/s10591-009-9106-6

Keywords: teaching family systems theory | family therapy training | developmental constructivism | systemic change

\title{
Teaching Family Systems Theory: A Developmental-Constructivist
}

\section{Perspective}

\section{Karen Caldwell and Chuck Claxton}

\begin{abstract}
Kegan's (1994) "In Over Our Heads" phenomenon has much to offer those who engage in teaching family systems theory and therapy, particularly in relationship to the tensions involved in the potential mismatch between the developmental demands of the curriculum and orders of consciousness which characterize students' responses to the material. One useful way to think about teaching in ways that address the phenomenon that Kegan has named is David Kolb's (1984) theory of experiential learning. Specific applications of this theory to teaching family systems theory are presented, as well issues involved in professional development based on the challenge this Kegan and Kolb developmental-constructivist perspective brings to department or program culture in which a family systems theory curriculum operates.
\end{abstract}




\section{ARTICLE}

Many challenges currently face marriage and family therapy (MFT) educators. While standards of education in MFT allow flexibility for individual programs, they also require clear foundational elements and increasingly call for educators to show that students are competent in their field of study (Nelson \& Smock, 2005). Evaluating student competencies involves a set of complex questions and problems not the least of which involves developmental considerations. MFT students must be able to think systemically, to view a context in terms of its parts and the connections among them that make it a whole. This ability requires achievement of a certain level of cognitive development as the following example shows.

\section{Evaluating Systemic Awareness: An Example}

An aim of my (author's initials) introduction to family therapy theories course was for students become more sensitive to the values inherent in different theories. On the first day of class, I distributed to students the assignment for their final essay: "Choose any two family therapy theories we have dealt with in class and critique them on how the theories do or do not reflect sensitivity to culturally different clients. Describe the theories including the values of each one as well as their relationship to diversityrelated issues such as race, class, ethnicity, age, gender, sexual orientation, ability, spirituality, and/or religion." The class sessions during the semester dealt with these theories and the cultural implications of each one. 
Towards the end of the semester, one student asked, "What exactly are values of theories?" We agreed that we would devote the next class session to working on that question. At the session I created a chart with the names of five theories in a vertical column down the side of the board and topics listed horizontally across the top of the board, such as theoretical constructs, goals, techniques, values, and cultural considerations. The students easily contributed to the constructs, goals, and techniques of the various theories. However, the values and cultural considerations came more slowly for them. The essays I received at the end of the semester varied greatly in quality. About half the class had personalized the material and applied and extended the in-class examples to their own life experiences. They clearly "got it." However, the rest of the students essentially regurgitated (to use the formal, academic lingo!) what was on the chart the class had composed on the chalk board.

This example probably sounds familiar to experienced faculty members who teach family therapy. It would be easy to slip into the frustration reflected in the wry question frequently posed by developmental stage theorist William Perry (1999) in workshops: "Why do students learn so poorly that which I have taught so well?" Robert Kegan (1982, 1994), who was a student of Perry's at Harvard and is now a leading stage theorist himself, would probably respond to the example as follows: "Maybe some of the students are 'in over their heads'."

This article examines Kegan's (1994) In Over Our Heads phenomenon and its relationship to teaching family therapy, particularly the tensions inherent in teaching family systems theory. It then applies David Kolb's (1984) theory of experiential learning to teaching in ways that address the phenomenon that Kegan has named. It then considers 
implications for professional development given the challenge that this Kegan and Kolb developmental-constructivist perspective brings to a department or program culture in which a family systems theory curriculum operates.

\section{The In Over Our Heads Phenomenon}

Kegan $(1982,1994)$ has identified several stages or orders of consciousness in adulthood: the interpersonal self, the institutional self, and the interindividual self (see Table 1). He estimates that less than $10 \%$ of adults in the US ever reach the fifth order of consciousness, that is the stage of interindividual self consciousness. Hence, the major interests of this article are the interpersonal self (third) and the institutional self (fourth) orders of consciousness.

Table 1. Orders of Consciousness in Adulthood (Kegan, 1994)

\begin{tabular}{|l|l|l|}
\hline \multicolumn{1}{|c|}{ THIRD ORDER } & \multicolumn{1}{|c|}{ FOURTH ORDER } & \multicolumn{1}{c|}{ FIFTH ORDER } \\
\hline The Interpersonal Self; & The Institutional Self; & The Interindividual Self; \\
(the Socialized Mind) & (the Self-authoring Mind) & $\begin{array}{l}\text { (the Self-transforming } \\
\text { Mind) }\end{array}$ \\
\hline $\begin{array}{l}\text { The self is embedded in its } \\
\text { relationships and its }\end{array}$ & $\begin{array}{l}\text { The self } \text { has its } \\
\text { relationships }\end{array}$ & The self has its "institution" \\
surroundings & & \\
\hline "I am my relationships" & "I am my institution" & \\
\hline
\end{tabular}




\section{The Interpersonal Self}

Every stage has its strengths and its limitations. Persons in the third order, for example, have the capacity for empathy, thus enabling them to experience a shared reality with others. They can engage in relationships for their own sake, rather than simply for an instrumental payoff they might receive. Persons in this order of consciousness can coordinate more than one point of view internally and create the experience of emotions as internal subjective states, rather than as simply social transactions. On the other hand, persons in the third order have a sense of identity that is essentially codefined. They have absorbed the values, beliefs, and assumptions they hold from their environment. They are not able to construct a generalized system regulative of interpersonal relationships and relationships between relationships. And they cannot distinguish the self from its relationships or see the self as the author of their inner psychological life.

\section{The Institutional Self}

In contrast to persons at the third order, persons at the next stage of meaningmaking can distinguish and organize their feelings into a whole so that they experience themselves as being guided by internal visions and values. Relationships are based on the capacity to create and recreate roles rather than simply adhering to role demands. Persons at this order can exercise critical thinking and are self-directed in their learning and in their life generally. They can separate what they value from what the society says they 
"should" value. They see themselves as cocreators of culture and take responsibility for themselves both internally and externally.

Like the other orders of consciousness, however, this self-authoring or institutional mind has its limitations. Fourth order is embedded in its own "institution" (its way of operating) and cannot stand aside from it and question the principles upon which the self is constructed. Its focus on self-authorship, self-regulation, and selfformation leads to a logic that is self-sealing. As a result, persons at this stage are not able to critique the process by which the self is carrying out its "work."

\section{Orders of Consciousness and the Demands of Family Therapy}

Kegan (1994) has examined the mental demands described by leading edge thinkers in various domains of modern life, including the work setting, partnering, dealing with differences, and adult education. He says that the demands articulated by these writers appear quite different at first, yet they all seem to be calling for a certain order of mind or level of consciousness: It is the fourth order. So at what order are most adults in the US? According to Kegan, "At any given moment, around one-half to twothirds of the adult population appear not to have fully reached the fourth order of consciousness" (1994, pp. 188, 191). So the culture generally finds itself in a bind. The mental demands of modern life call for fourth order consciousness, but most adults are in the third order. We are, Kegan concludes, in over our heads.

In all likelihood, the students who had trouble identifying the values inherent in different theories are also in over their heads. To state the obvious, family systems therapy rests on the assumption that a family is a system. It is made up of persons who 
are interconnected, and their actions, thoughts, beliefs, and attitudes impact the other members and the system as a whole. Persons at the fourth order of consciousness instinctively understand systems thinking, but persons at third order do not. In looking at organizations, for example, Kegan (1994) says that persons at the fourth order can:

... conceive of the organization from the "outside in," as a whole; see [their] relation to the whole; see the relation of the parts to the whole (rather than see the rest of the organization and its parts only from the perspective of [their] own part, from the "inside out). (p. 302)

The same logic applies to the ability to see families as systems. The students in

the example who had so much trouble discerning the values embedded in theories may well be at third order. As indicated earlier, persons at that stage have absorbed their values, beliefs, and assumptions from their environment. Because they are embedded in these values and therefore are subject to them, they are not able to stand aside from them and assess their soundness. In contrast to this third order epistemological stance, persons at the fourth order have questioned the values received from others and have chosen and developed their own. This capacity to stand aside from their own values, to consider them as object rather than being subject to them, enables the students to see and evaluate values as a whole, including those inherent in theories of family systems.

At what order of consciousness are graduate students studying family therapy in programs in the US? We know of no research that answers that question, but related research (and our own experience) would suggest that many students in master's level 
programs are not yet fully in the fourth order. For example, Parks' (1993) study of MBA students at Harvard found that most of them were in the third order. Granello (2002) conducted a study of 205 master's level students in counseling programs at 13 colleges and universities who were near the completion of their programs. She found that none of them had reached the stage Perry (1999) calls relativism, a system of thought that is roughly analogous to Kegan's (1994) fourth order of consciousness. According to Granello, her findings were "consistent with the results of other research" (p. 290) on graduate students.

How can faculty in graduate programs teaching family systems theory create curricular contexts which support students' development towards and into fourth order consciousness? There is no single answer to this question, of course, but David Kolb's (1984) theory of experiential learning is an excellent guide to the kinds of learning that support students' development as depicted by Kegan $(1982,1994)$ and other stage theorists. 


\section{The Kolb Model}

\section{A Theory of Experiential Learning}

In Kolb's (1984) view, the most effective learning occurs when students engage in a four-step process: concrete experience, reflective observation, abstract conceptualization, and active experimentation (see Figure 1). In concrete experience,

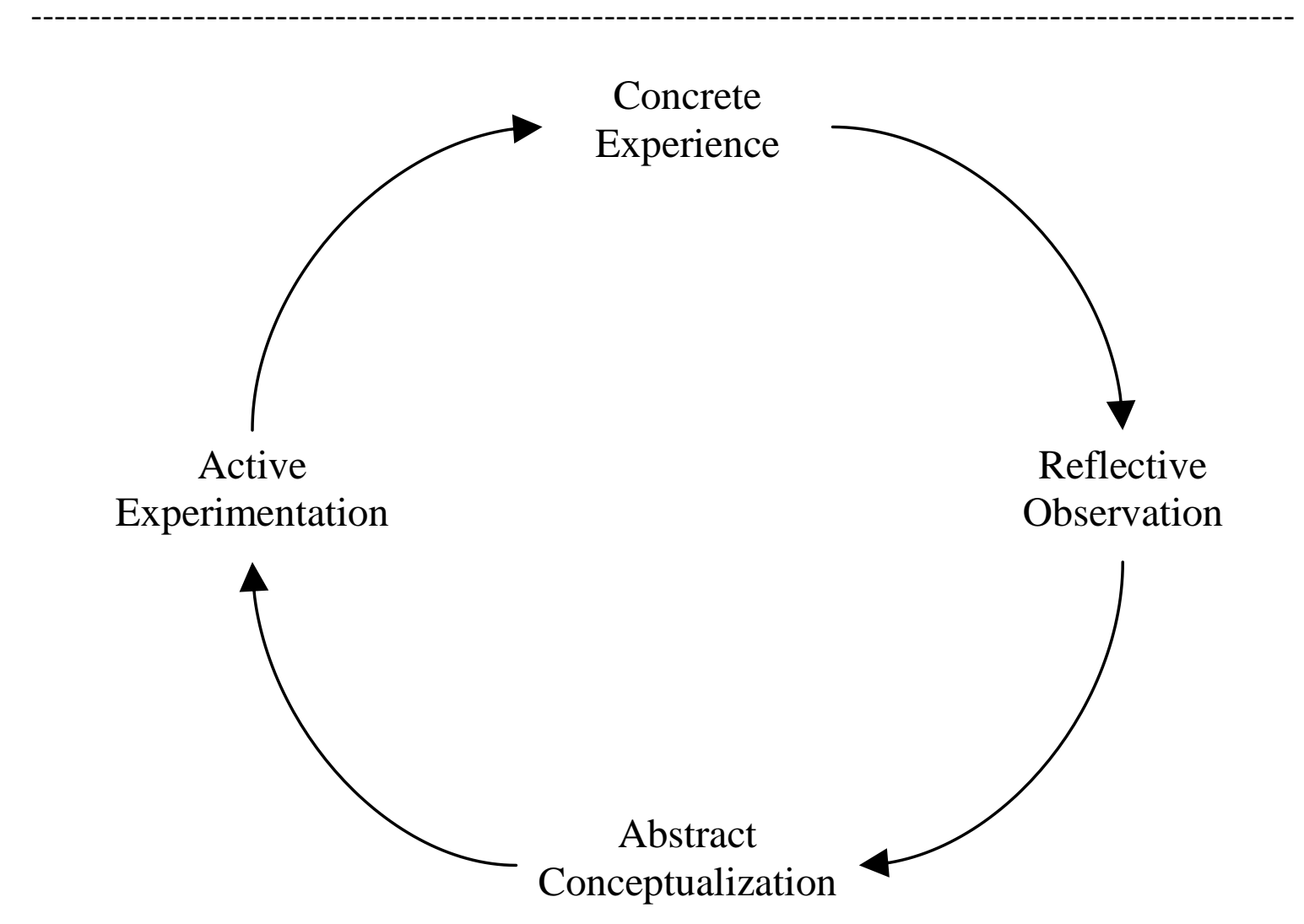

Figure 1. The four modes of the experiential learning cycle.

Kolb, D. (1984). Experiential Learning: Experience as the Source of Learning, p. 42.

Adapted with permission of Pearson Education, Inc., Upper Saddle River, NJ.

students engage in hands-on activities. In reflective observation, they look back on this 
subjective experience and ask related questions: What was that like? Have I ever had an experience like before? How did that feel? Students then engage in abstract conceptualization where they examine larger perspectives provided by theory and research from the disciplines or from other authoritative sources which enable them to view their concrete experience and their reflections on it from a more objective perspective. The students then use these theories or principles as guides to further action or active experimentation. Students generally have another concrete experience but this time at a more complex level. This is followed by reflective observation, abstract conceptualization, and active experimentation. The Kolb model is a circle, but it may be better thought of as a spiral, one in which students move through the four modes again and again at increasing levels of complexity.

Figure 2 illustrates the important distinction between the vertical axis of concrete experience-abstract conceptualization and the horizontal axis of reflective observation- 
active experimentation in the Kolb model. In this depiction of the cycle, learning occurs -

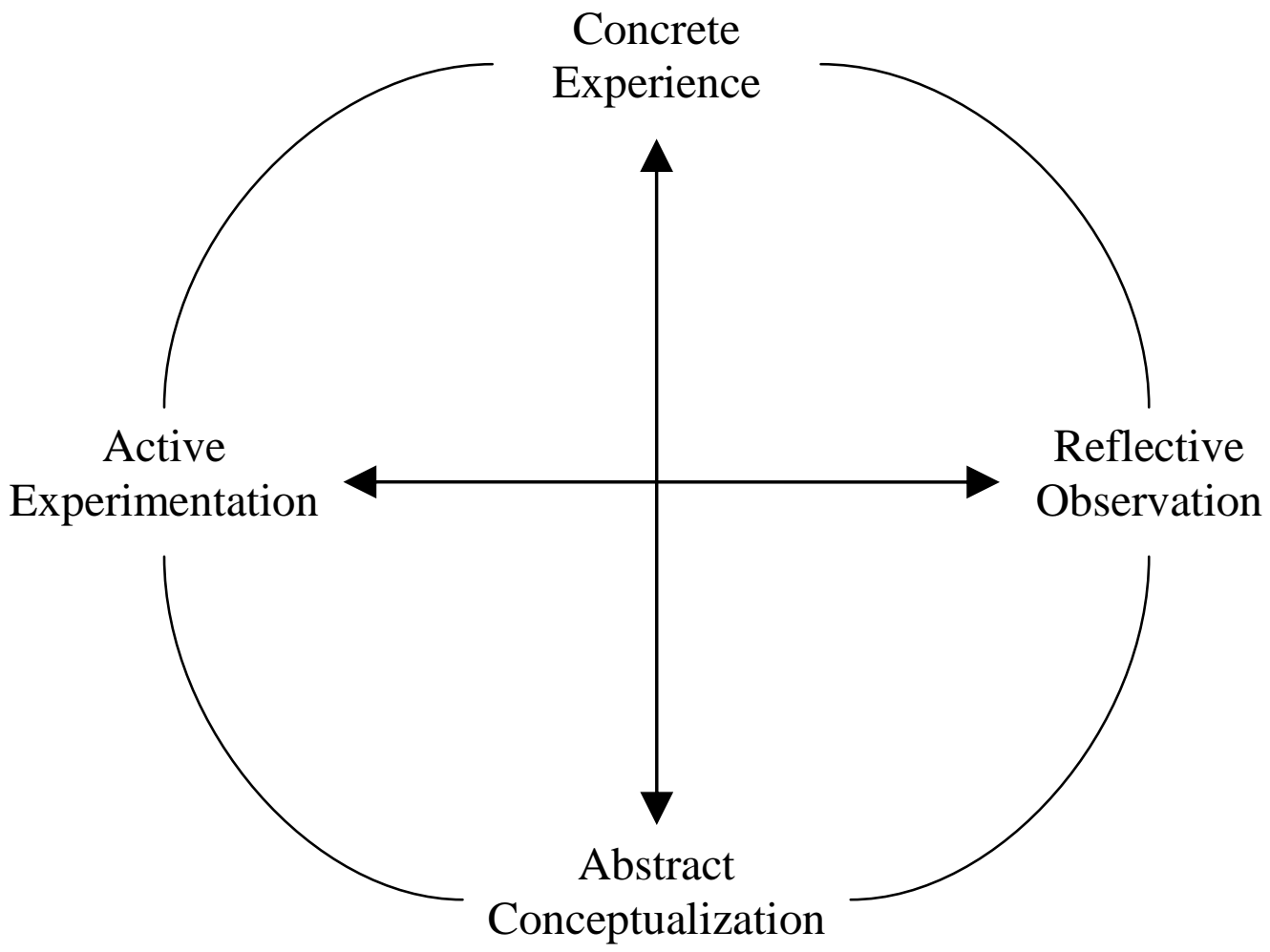

Figure 2. The vertical axis of the experiential learning cycle represents the prehension of information or experience; the horizontal axis represents the construction of information or experience.

in two steps. First, students prehend or "take hold of" experience or information on the vertical axis, and they may do this through concrete experience or abstract conceptualization. Second, they transform or make meaning of the experience they have prehended on the horizontal axis, and they may do this through reflective observation or active experimentation. 


\section{Teaching Example \#1}

We turn now to an examination of teaching guided by the Kolb (1984) theory of learning. Let us assume that a major learning outcome of the family therapy program is for graduates to be able to operate from a systems theory framework in their role as therapists. A learning objective at the course level that contributes to such a program outcome is to help students learn to develop hypotheses regarding relationship patterns and their bearing on presenting problems and explain how these relate to systems theory (see Figure 3). In an assignment for concrete experience, students are asked to look back

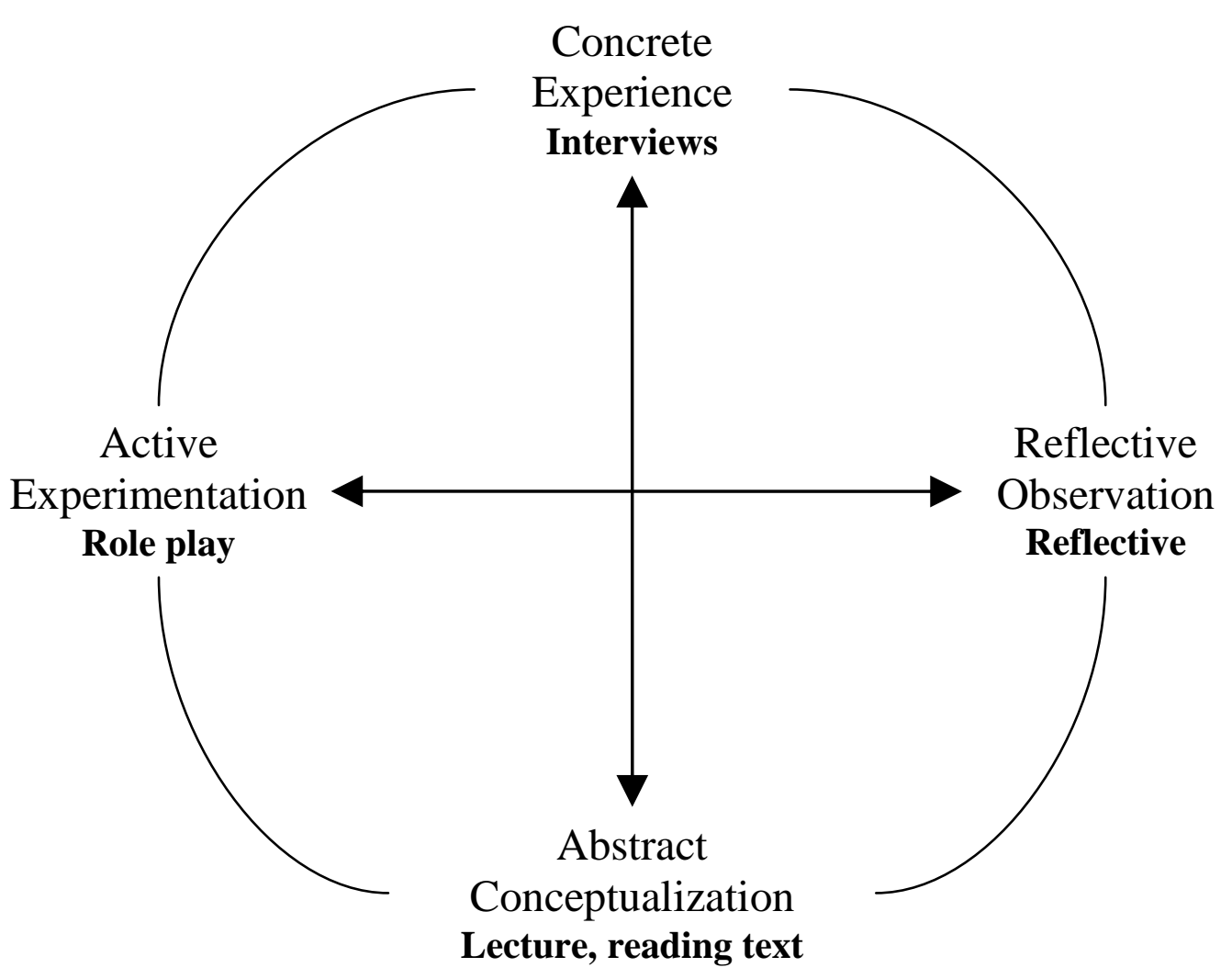


Figure 3. Teaching Example \#1. Application of Kolb's experiential learning cycle to the learning objective: To help students learn to develop hypotheses regarding relationship patterns and their bearing on presenting problems and how these relate to systems theory.

on their own lives and describe successful and unsuccessful strategies they themselves have used to improve relationships with others. They then interview three to four persons and ask them to do the same thing.

For guided experience related to reflective observation, students prepare a brief paper in which they comment on the strategies they themselves have used in their own lives to improve relationships as well as strategies identified by their interviewees. They explain their reactions to two experiences, asking themselves such questions as: Were there commonalities in the strategies they and the interviewees identified? What were the feelings of the interviewees as they talked? Did they themselves experience any particular feelings in the process (e.g., surprise, confirmation, discouragement)? In the next class session, the students work in small groups and share their findings.

For the next phase, abstract conceptualization, students in the course are asked to read a section in the textbook prior to the next class which describes fundamental concepts of family therapy such as boundaries, feedback, and circular causality. In the subsequent class session, the instructor draws parallels between the relationship experiences students described in their reflective observation interviews and the concepts in the reading. The instructor then notes that these concepts were developed by the founders of family therapy to describe human behavior as fundamentally organized by its 
interpersonal context and discusses the basic concepts of systems theory drawn from the reading assignments and the discipline in general.

At the next session the instructor asks two students to act in a role play as cotherapists and two other students to play the part of a married couple. She helps the cotherapists focus on developing a systemic hypothesis of the couple's problem at various points in the role-play. She asks the other students to be observers and, at the same time, develop their own systemic hypotheses. Afterwards, the instructor helps the students process what went on in the role play (another reflective observation activity), focusing on their subjective reactions to what has happened and generating insights from a systems perspective about effective therapy.

\section{Teaching Example \#2}

The next example comes from an Assessment in Marriage and Family Therapy course, and one of its learning objectives is to help students develop the ability to diagnose and assess client behavioral and relational problems systemically and contextually and, at the same time, understand current models (usually medical models) for assessment and diagnosis of mental health disorders (see Figure 4). Earlier in the curriculum, the students are briefly introduced to diagnosis through traditional medical models and systemic/contextual models. In the assessment course, the instructor directs the students to work alone for several minutes and make notes concerning their 


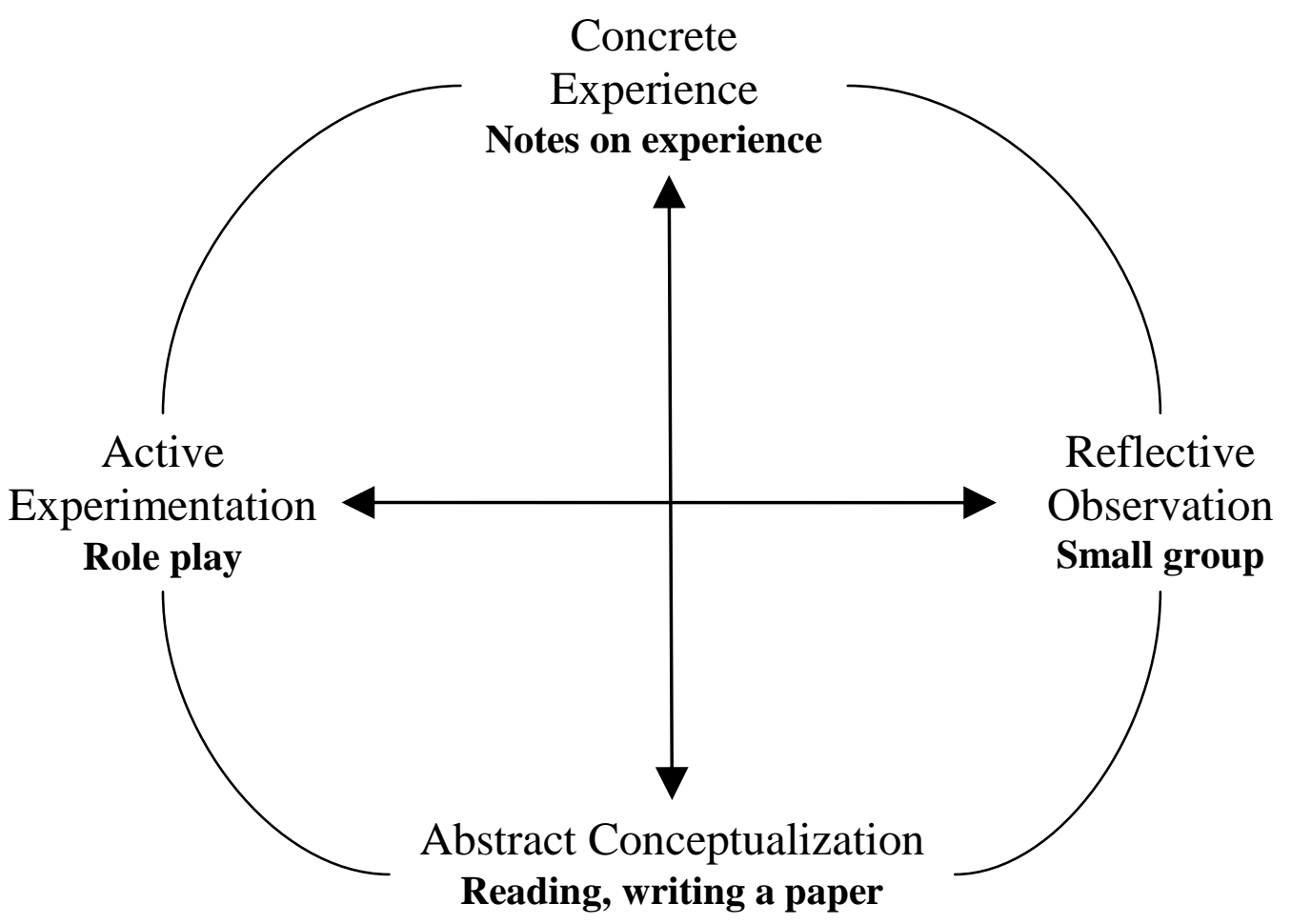

Figure 4. Teaching Example \#2. Application of Kolb's experiential learning cycle to the learning objective: To help students develop the ability to diagnose and assess client behavioral and relational problems systemically and contextually.

experiences of either being diagnosed themselves or the experiences of friends and/or family members' experiences of being diagnosed (concrete experience). Next, to engage in reflective observation, the students work in small groups with each member sharing their experiences. The group then tries to reach consensus on whether each diagnosis was developed using traditional medical models or systemic/contextual models and the 
provide reasons for their views. The teacher then asks each group to make an oral report on their work, giving particular attention to the insights they are developing concerning traditional medical models and systemic/contextual models.

For abstract conceptualization, students are asked to read a series of articles on medical models and systemic/contextual models of assessment. After in-class discussion about the different theoretical models, students are asked to apply diagnostic criteria from both models to several cases as an exercise (active experimentation). Students then videotape themselves engaging in role plays of an initial session with a client (further active experimentation) and present these tapes to the class for discussion and feedback. Students write up their diagnostic impressions of their role-played clients using the five axes of the Diagnostic and statistical manual of mental disorders-IV-TR (American Psychiatric Association, 2000) along with a systemic/contextual description of the client's situation.

\section{Teaching for Development}

To repeat, the organizing question for this paper is, How can faculty in programs teaching family systems theory create curricular contexts which support students' development towards and into fourth-order consciousness? We believe teaching that uses Kolb's theory of experiential learning as a guide to teaching, as reflected in the teaching examples provided, fosters their development as depicted by the Kegan framework. The reasoning behind this statement can be best be understood through an examination of the assumptions which form the foundation of the experiential learning cycle. 
In our view there are four foundational assumptions undergirding the experiential learning cycle. The first is that learning is more effective if students engage with what is to be learned in all four modes of the cycle: concrete experience, reflective observation, abstract conceptualization, and active experimentation. In Kolb's (1984) phrasing, it is the "combination of all four . . learning modes" that produces "the highest level of learning” (p. 66). Such an assumption stands in contrast to assumptions inferred from much traditional teaching which consists of the professor conveying information to students who (hopefully) take notes and think about what the lecturer is saying.

The second assumption is that learning consists of prehending information or experience (the vertical line) and transforming it for one's self (the horizontal line). In this social constructivist view, Kolb (1984) says that knowledge is not simply "an independent entity to be acquired (by the learners) or transmitted" (p. 38) by the professor. Rather, "knowledge is a transformation process, being continuously created" by the students. More specifically, he conveys that students take in information or experience through concrete experience and abstract conceptualization; they transform, construct, or make meaning of what they have prehended through reflective observation and active experience. This process was demonstrated in Teaching Example \#1 (see Figure 3). The students' concrete experience consisted of making notes of their own experience to identify patterns of relationships as well as interviewing others about the patterns that they had experienced. They also prehended information or experience through reading and listening to lectures on concepts such as boundaries, feedback, and circular causality as seen from a systems perspective (abstract conceptualization). They were engaged in reflective observation when they wrote papers on what they had learned 
in the interviews along with a discussion of their reactions to those events. There was active experimentation when they participated in a co-therapist role play (either as actors or as observers) and developed systemic hypotheses of the married couple's problem.

The next assumption is that concrete experience and abstract conceptualization are equally potent. With this assumption, Kolb (1984) has moved beyond the outmoded (though still dominant) mindset in education that privileges objectivist knowing and holds subjectivist knowing at the margins. He uses the term apprehension to refer to the knowing that comes through concrete experience and comprehension to refer to the knowing that comes through abstract conceptualization (see Figure 4). Apprehension is characterized by appreciation, an empathetic, believing stance, whereas comprehension is characterized by criticism, an analytic, detached, and skeptical posture that steps back from the here-and-now experience. Readers familiar with the book, Women's Ways of Knowing, by Belenky, Clinchy, Goldberger, and Tarule (1997), will hear the resonance between this depiction of concrete experience-abstract conceptualization and their framework, connected knowing-separate knowing. In their research, Belenky et al. found that higher education's overemphasis on separate knowing had a detrimental impact on female students, many of whom were more oriented to connected knowing. The dominance of objectivist knowing may also make learning on the part of persons of color more difficult as well. Anderson and Adams (1992) have found that "while white females and African-American, Native-American, and Hispanic-American males and females fall toward the relational end of the continuum, ... Euro-American and AsianAmerican males fall toward the analytical ... end of the spectrum" (p. 23). 
The last assumption which underlies the experiential learning cycle is stated best by Kolb (1984): “The process of learning that actualizes development requires a confrontation and resolution of the dialectic conflicts inherent in experiential learning" (p. 134). This assumption harkens back to Heraclitus' statement that "In the tension between the opposites, all things have their being." Students move towards greater complexity of meaning making as they integrate what they have learned through the polar opposites of concrete experience-abstract conceptualization and reflective observationactive experimentation. The teacher in "Teaching Example \#2" led the students into concrete experience when she asked them to look back on any experiences they or other persons they knew had had of being diagnosed by a mental health professional. She led them into theory and research (abstract conceptualization) when she asked them to compare and contrast diagnoses that would emanate from medical models versus systems models. Learning through the subjectivity of concrete experience often feels different from learning through the objectivity of abstract conceptualization, and whatever disequilibrium or dissonance students experience in the process can create an occasion of being caught up short, of realizing that the way they had been thinking about the issue at hand is now shown to be either somewhat off the mark or, in some cases, radically different. Students are then left to experience the disequilibrium caused by polar opposites - the type of experience that Kolb says leads to development.

Similarly, the students were operating in the tension between the opposites of reflective observation and active experimentation. In the first example, they worked in small groups to determine whether the diagnoses they or others had received reflected the 
assumptions embedded in medical models or systems models. In the second, they engaged in role plays and practiced applying diagnostic criteria from both models.

\section{Implications for Professional Development}

Thus far we have used Kegan's $(1982,1994)$ theory of adult development to suggest that programs orient their teaching to support students in their journey towards and into fourth-order consciousness. We have drawn on Kolb's (1984) theory of experiential learning to show one way of thinking about teaching for development, specifically that faculty engage students "in the in-between" of concrete experienceabstract conceptualization and reflective observation-active experimentation. A third order construal of the preceding discussion is that faculty in these programs should simply "teach around the circle," systematically engaging students in the four modes. It is, of course, more complex than that. A fourth-order perspective recognizes that individual faculty members will only teach in ways that are consistent with their own assumptions about teaching, learning, and their role as teachers. This perspective recognizes also that how individual faculty teach is heavily influenced by the culture of the program or department of which they are a part.

\section{Individual and Small-Group Level}

The discussion that follows sketches the kind of journey that individual faculty members and the program in which they work will take to create a setting and an environment that genuinely support the development of their students towards and into fourth-order consciousness. We have enumerated what we take to be Kolb's four 
assumptions about promoting learning and development. The issue for persons who teach family systems theory, however, is not so much Kolb's assumptions about teaching for development but their own assumption. The value of the Kolb cycle is two-fold: (a) it provides a rich, multilayered mental model of teaching oriented to development, one which is instructive for faculty oriented to that goal; (b) it is a vehicle faculty can use to stimulate thinking more deeply about their own assumptions.

A challenge that gets in the way of faculty determining with some precision their mental model of teaching is that many are not clear as to what their assumptions actually are. In most organizations, people routinely share their opinions but seldom talk about the assumptions that lead to their opinions. As a result, their assumptions remain in place, "below the surface of the mind and, like the admiral of a submerged submarine fleet, control from the depths" (Hall, 1981, p. 42). Further, what faculty members report about how they teach is sometimes at odds with how they actually teach, as revealed in interviews and classroom observations (Grubb et al., 1999). Argyris and Schön (1996) have labeled this common phenomenon "the gap" between espoused theory and theoryin-use. Reasons for this gap are not surprising. For example, with today's emphasis on collaborative learning in higher education, faculty will say that is exactly what they foster in their classroom. Yet the dominant mode of teaching in higher education is through lecture, and faculty who are primarily oriented to this approach may, in fact, be uncomfortable with the messier, more unpredictable classroom characterized by collaborative learning and shy away from this approach.

How can faculty who wish to orient their teaching more to teaching for development get greater clarity not only about their espoused theory of teaching but also 
their theory-in-use? There is no single answer to this question. But the following scenario is one example that illustrates what is involved.

The individual work called for in this process can best be done, paradoxically, in community. (In this case, we define community as a group of two or possibly three people). To get started, each of the faculty members selects a course as the focus of their professional development for a semester. Working alone, each person begins by responding to this question:

1. What content and what teaching processes in the course presently seem oriented to supporting students' development towards fourth-order consciousness?

The faculty members then set down in writing examples from their teaching during which they sensed students were engaged in the kind of deep learning that is called for toward fourth-order development. They then distill from the examples the four or five beliefs or assumptions about effective learning undergirding the examples that make most sense to them. They think of these assumptions as their "mental-model-in-progress" of teaching for development. They then review the syllabus and instructional materials for the course and note where the course plans are consistent with or inconsistent with the assumptions they have listed.

Once that part of the process has been completed, the members of the small group meet to share their list of assumptions about deep learning as well as their findings from the review of their syllabus and instructional materials. Next, they respond to subsequent questions derived from the Kolb (1984) model: 
2. At what points in the course will students be prehending information or experience through concrete experience? And through abstract conceptualization?

3. Are the concrete experiences juxtaposed with the abstract conceptualization activities in such a way that students will experience a creative tension between knowing through subjectivity and knowing through objectivity?

4. At what points in the course are learning activities geared to reflective observation? and to active experimentation?

5. Are the opportunities for reflective observation and active experimentation juxtaposed so that students experience a creative tension between these two modes of the learning cycle?

The faculty members of the small group use their learnings from the meeting to make changes in their course plans to fully integrate all of Kolb's modes of experiential learning. They schedule dates and times to observe each other's teaching two to four times in the semester, followed by face to face meetings. Here they share what they are learning about teaching and learning, the Kolb cycle, and ways in which these experiences are impacting the assumptions they enumerated earlier.

Meetings in which the members are not honest with each other about what they see (including those instances where the teaching in which they see their colleague engaged in the classroom seems to be ineffective) are not worth much. Yet, as Palmer (1998) reminds us, we teach who we are. It is essential, therefore, that the process described above, as well as the meetings the faculty members have, be characterized by trust, care, and mutual respect. Further, the members must be aware that the feedback they provide for each other needs to be characterized by a dialogic process in which how 
they interpret what they have seen in the classroom is in fact their construction of what happened and not necessarily what actually occurred.

It is clear from the professional development scenario described that the two faculty members are bringing their own assumptions about teaching for development into conversation with Kolb's assumptions. This process does not seek to impose on faculty a single model for teaching and learning but, rather, tries to honor the assumptions that teachers of marriage and family therapy bring to their work. This kind of individual and small-group work will result not in teachers simply adopting Kolb's (1984) assumptions. Rather, we anticipate that what will emerge for the teachers involved is a mental model that is richer than and different from the list of assumptions they begin with. Further, it will be richer than and different from Kolb's assumptions. This is because the emerging mental model will be their own: critically examined, tested in real time, and "lived into" by the participating teachers.

\section{Program or Department Level}

An adage among experts in institutional development is that the culture of an organization is designed perfectly to produce the kinds of thinking and practices it now employs. This means that if most of the teaching in a family therapy program is not oriented to helping students move towards increasingly complex levels of meaning making, the program's present culture is not supportive of that goal. This further suggests that helping faculty members learn to teach more explicitly for development is not simply an individual issue; rather, it involves a form of systemic, cultural change. 
Woodrow Wilson once said that changing a curriculum is as hard as moving a graveyard. Changing the culture of an institution or a program is just as hard. However, a helpful insight that change theorists are realizing is simple yet potent: The culture of programs change only as the persons within them change (Wagner et al., 2006). But what kind of change is Wagner et al. pointing to? A change in which faculty members work together to surface, examine, and change their assumptions about good teaching as illustrated in the preceding scenario. How might a family therapy program which is not particularly oriented to development create the kind of culture that would support such a goal?

\section{Conclusion}

With committed faculty and good leadership, the kind of work done by the small group of faculty described in this article could be replicated. A helpful metaphor for a program's culture is that of an ecological zone. An ecology can be changed (for better or worse) by introducing just one new element or process into it. The ideas behind family systems theory turn back on themselves. Family therapy faculty know its importance in working with clients. The principles of systems theory can also be used to guide the work of a program in altering its culture. This line of thought supports the notion that the work carried out by a small group as illustrated in the preceding scenario is no small thing. Such an approach to changing assumptions about teaching for development, when encouraged and nurtured by wise leadership, can be carried out by others such that, in time, the faculty reach a tipping point where the culture itself begins to shift. 


\section{References}

American Psychiatric Association (2000). Diagnostic and statistical manual of mental disorders $\left(4^{\text {th }}\right.$ ed. Text Revision). Washington, DC: Author.

Anderson, J. A., \& Adams. M. (1992, Spring). Acknowledging the learning styles of diverse student populations. In L. B. Border \& N. V. N. Chism (Eds.), Teaching for diversity (pp. 19-33). San Francisco: Jossey-Bass.

Argyris, C., \& Schön, D. A. (1996). Organizational learning II: Theory, method, and practice. Reading, MA: Addison-Wesley.

Belenky, M. F., Clinchy, B. M., Goldberger, N. R., \& Tarule, J. M. (1997). Women's ways of knowing: The development of self, voice, and mind. New York: Basic Books.

Granello, D. H. (2002, June). Assessing the cognitive development of counseling students: Changes in epistemological assumptions. Counselor Education \& Supervision, 41, 279-293.

Grubb, W. N., Worthen, H., Byrd, B., Webb, E., Badway, N., Case, C., Goto, S., \& Villeneuve, J. C. (1999). Honored but invisible: An inside look at teaching in community colleges. New York: Routledge.

Hall, E. T. (1981). Beyond culture. New York: Anchor.

Kegan, R. (1982). The evolving self: Problem and process in human development. Cambridge: Harvard University Press.

Kegan, R. (1994). In over our heads: The mental demands of modern life. Cambridge, MA: Harvard University Press. 
Kolb, D. A. (1984). Experiential learning: Experience as the source of learning and development. Englewood Cliffs, NJ: Prentice-Hall, Inc.

Nelson, T., \& Smock, S. (2005). Challenges of an outcome-based perspective for marriage and family therapy education. Family Process, 44(3), 355-362.

Palmer, P. J. (1998). The courage to teach: Exploring the inner landscape of a teacher's life. San Francisco: Jossey-Bass.

Parks, S. D. (1993). Is it too late? Young adults and the formation of professional ethics. In T. R. Piper, M. C. Gentile, \& S. D. Parks (Eds.), Can ethics be taught? Perspectives, challenges, and approaches at Harvard Business School (pp. 1372). Boston, MA: Harvard Business School.

Perry, W. G. (1999). Forms of intellectual and ethical development in the college years. San Francisco: Jossey-Bass.

Wagner, T., Kegan, R., Lacey, L., Lemons, R. W., Garnier, J., Helsing, D., Howell, A., \& Rasmussen, H. T. (2006). Change leadership: A practical guide to transforming our schools. San Francisco: Jossey-Bass. 